\title{
MORTALITY
}

\section{Excess cardiac mortality on Monday: the importance of gender, age and hospitalisation}

\author{
D.R. Witte, D.E. Grobbee, M.L. Bots \& A.W. Hoes \\ Julius Center for Health Sciences and Primary Care, University Medical Center Utrecht, Utrecht, The Netherlands
}

Accepted in revised form 22 November 2004

\begin{abstract}
Background: Available evidence suggests a peak in the incidence of cardiovascular events on Mondays compared to other days of the week. The underlying mechanism may be summarised as naturally occurring rhythmic fluctuations in human physiology, and socially determined rhythms in human behaviour. Change in these rhythms may lead to attenuation of the peak on Mondays. Objective: To quantify the excess risk associated with the Monday peak in cardiovascular mortality and to explore the role of age, gender and hospitalisation. Methods: Details on time and cause of all deaths which occurred in the city of Rotterdam between November 21, 1988 and November 21, 1990 were obtained by sending a questionnaire to the physician who signed the death certificate. We studied the weekly distribution of 1828 confirmed cases of sudden cardiac death, for the group as a whole and in subgroups according to gender, age ( $<65$ years $/ 65$ years) and
\end{abstract}

hospitalisation. Results: The odds ratio (OR) of sudden cardiac death on Monday compared to other days of the week was 1.20 (95\% CI: $1.06-1.36)$. The excess mortality due to the Monday peak amounted to 4.9 per 1000 deaths. The Monday peak was more pronounced in non-hospitalised (OR: 1.25; 95\% CI: 1.08-1.44) than in hospitalised patients (OR: 1.06; 95\% CI: $0.83-1.37$ ), in men (OR: 1.25 ; 95\% CI: $1.06-1.48$ ) than in women (OR: $1.14 ; 95 \% \mathrm{CI}$ : 0.95-1.36), and in those younger than 65 (OR: 1.29; 95\% CI: $0.95-1.74)$ compared to those aged 65 years or over (OR: 1.18; 95\% CI: 1.03-1.35). Yet, the confidence limits overlap. Conclusion: The incidence of sudden cardiac death is markedly increased on Monday, more pronounced in non-hospitalised patients. Our results may point to the relevance of naturally occurring rhythmic fluctuations in human physiology, and socially determined rhythms in human behaviour as underlying mechanism.

Key words: Atherosclerosis, Cardiovascular disease, Circadian variation, Review, Sudden cardiac death

\section{Introduction}

A range of studies described cyclical patterns in cardiovascular mortality. Peaks have been identified between 6:00 and 12:00 [1], during winter months [2], and on Mondays [3, 4]. In a review of 30 reports on the circadian pattern (i.e. variation during the day) of cardiovascular events, Cohen et al. [1] estimated that $8.8 \%$ of all acute myocardial infarctions and $6.8 \%$ of sudden cardiac deaths, are attributable to the morning excess of cardiovascular mortality.

The main pathophysiological mechanism underlying cyclic patterns in cardiovascular events is thought to be 'triggering' or disruption of a vulnerable atherosclerotic plaque [5]. Several possible triggers have been suggested, including natural rhythmic fluctuations in fibrinogen, cortisol, endothelial function and sympathetic stimulus [6]; but also rhythms in human activity like the work-leisure cycle, mental stress, physical activity [7], weekend binge drinking [8] and watching an important football match [9]. Since these potential mechanisms may vary by age, gender and hospitalisation, we explored the weekly pattern in cardiac mortality with focus on these factors using data obtained from a study on occurrence of sudden cardiac death among the population of the city of Rotterdam.

\section{Methods}

\section{Study population}

As part of a population-based study on the association between recent cardiovascular drug use and sudden cardiac death, a registry of all sudden cardiac deaths in the city of Rotterdam was established for a period of two years, as described in detail elsewhere [10]. In short, all residents of Rotterdam, the Netherlands, with a sudden cardiac death between 21 November 1988 and 21 November 1990 were recorded. Sudden death was defined as death occurring within 1 hour of the onset of symptoms or as unwitnessed death. The death was considered to be of cardiac origin, unless data from the attending physician or evidence from hospital or autopsy records suggested a non-cardiac cause. The study was approved by the 
Table 1. General characteristics of the study population

\begin{tabular}{lc}
\hline General characteristics & $N=1828$ \\
\hline Age (years) & $76.1 \quad(12.2)$ \\
Gender (Men) & $48 \%$ \\
Hospital deaths & $27 \%$ \\
Interval between onset of symptoms & \\
and death & \\
$0-30$ min & $60.4 \%$ \\
$30-60$ min & $9.3 \%$ \\
Unwitnessed & $30.3 \%$ \\
\hline
\end{tabular}

Values are the mean (standard deviation) for age, and percentages for all other variables.

ethics committee of the Academic Hospital Dijkzigt/ Erasmus University, Rotterdam.

For 2 years, municipal authorities prospectively provided us with information on all persons aged 20 years or older who died in Rotterdam. The physicians who signed the death certificate were mailed a questionnaire comprising three short questions on the period between the onset of symptoms and the occurrence of death and the possibility of a noncardiac cause. We sent a questionnaire to physicians of 10,649 patients who were reported to have died of natural causes during the study period. A total of 8314 questionnaires was returned (a response rate of $78 \%$ ), and $7834(74 \%)$ contained adequate information on the circumstances of death. Responding physicians reported 1847 deaths as sudden cardiac deaths. About 19 patients were excluded because general practitioners refused to co-operate or because evidence of the time of death was not available. This yielded a study population of 1828 cases of sudden cardiac death. The physicians were unaware of the hypothesis underlying the current analysis.

\section{Data analysis}

Mortality due to sudden cardiac death (absolute number of deaths) was categorised according to the day of the week. To determine whether the risk of sudden cardiac death was higher on Monday compared to the other days of the week, the difference between the observed mortality on Monday was compared to the expected mortality assuming no weekly rhythm with a Chisquare statistic. The same analysis was repeated in subgroups of gender, age and hospitalisation.

\section{Results}

The mean age of the 1828 cases of sudden cardiac death studied, was 76.1 (SD: 12.2). $48 \%$ of cases was male, and $27 \%$ of deaths occurred in hospital. The risk of sudden cardiac death was highest on Mondays. The odds ratio (OR) of sudden cardiac death on Monday compared to other days of the week was
1.20 (95\% CI: 1.06-1.36). Based on the total number of deaths in Rotterdam in the study period $(10,649)$, the excess mortality due to the Monday peak amounted to 4.9 per 1000 deaths.

Among the sudden cardiac death patients, $30.3 \%$ was found unwitnessed. It might be that some of these cases found dead on Monday, had actually died during the weekend. However, the proportion of unwitnessed deaths on Monday (33.9\%) was not significantly increased compared to Saturday or Sunday (31.6\% and $31.3 \%$, respectively). Furthermore, repeating our analyses after exclusion of the group of unwitnessed deaths did not materially alter the findings.

Subgroup analysis demonstrated that the increased risk of sudden death on Mondays was more pronounced in men (OR: 1.25 ; 95\% CI: $1.06-1.48)$ than in women (OR: 1.14; 95\% CI: 0.95-1.36) (Figure 1), and in those younger than 65 (OR: $1.29 ; 95 \% \mathrm{CI}$ : 0.95-1.74) compared to those aged 65 years or over (OR: 1.18; 95\% CI: 1.03-1.35). Further, the Monday peak was more marked in non-hospitalised (OR: 1.25; 95\% CI: $1.08-1.44)$ than in hospitalised patients (OR: 1.06; 95\% CI: 0.83-1.37) (Figure 2).

\section{Discussion}

Our study of 1828 cases of sudden cardiac death showed a markedly increased risk of sudden cardiac death on Mondays. Subgroup analysis showed this relation to be more pronounced in non-hospitalised patients.

Even though the first study describing a weekly rhythm in the incidence of myocardial infarctions and sudden cardiac death dates back to 1980 [4], most attention has since been given to the circadian (within a day) and seasonal variation in cardiovascular events. The recognition of these patterns has helped greatly in the development of the concept of 'triggering' of cardiovascular events [11]. Direct evidence in favour of a role for any particular trigger, like stress or physical activity is difficult to obtain prospectively, since the 'state of exposure' of an individual to possible triggering factors can change from minute to minute. An alternative method of elucidating the determinants of the rhythmic fluctuations in cardiovascular mortality is to identify subgroups of individuals within a population, in whom the pattern does not occur. A good example of this approach is the identification of platelet aggregation as a mechanism behind the circadian pattern in myocardial infarction in the Physicians Health Study [12], by finding a clear circadian pattern in the placebo group, but not in the aspirin group. Similar evidence exists for an attenuation of the circadian pattern in patients using $\beta$-blockers [13-15], and for a more pronounced circadian rhythm in the elderly [16-18] compared to younger people. 

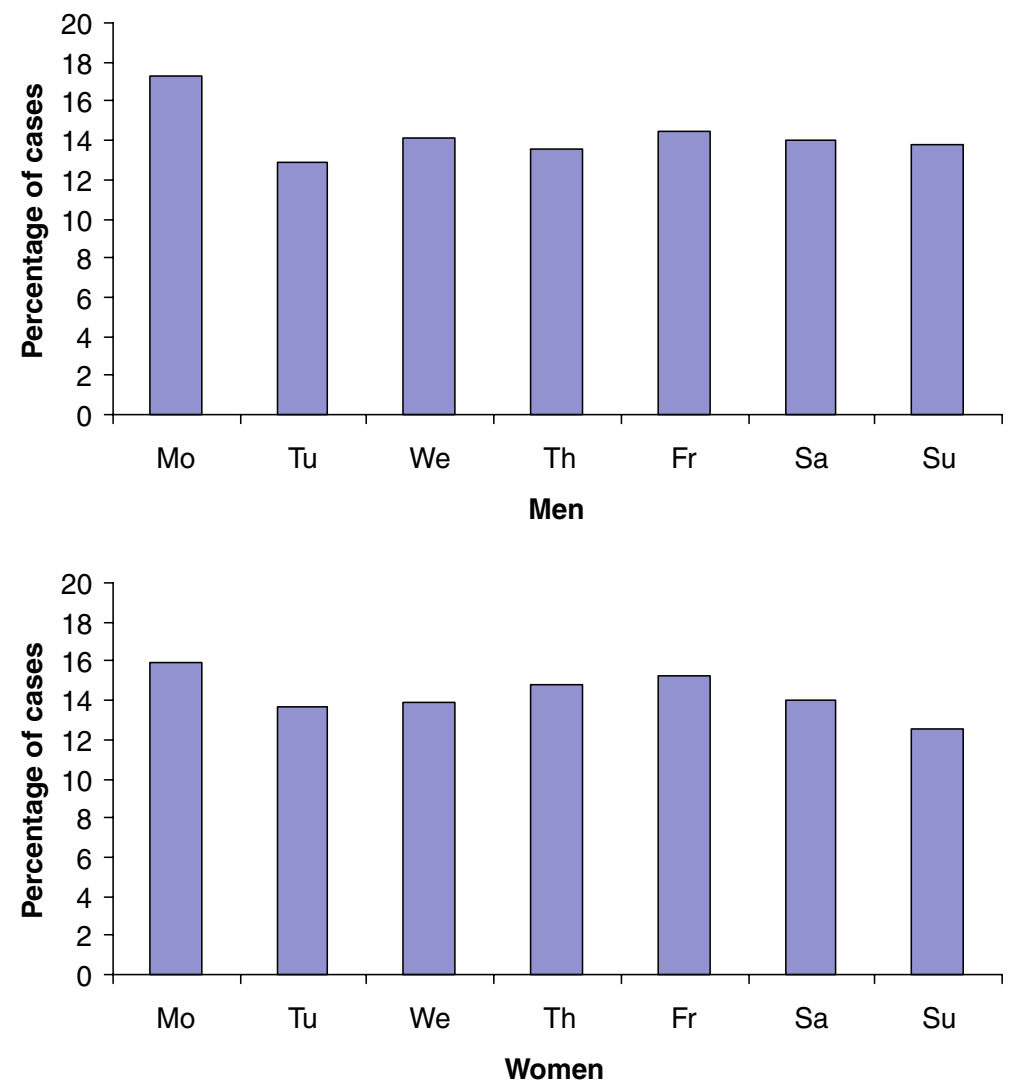

Figure 1. Sudden cardiac deaths in Rotterdam, per day of the week in men and women.
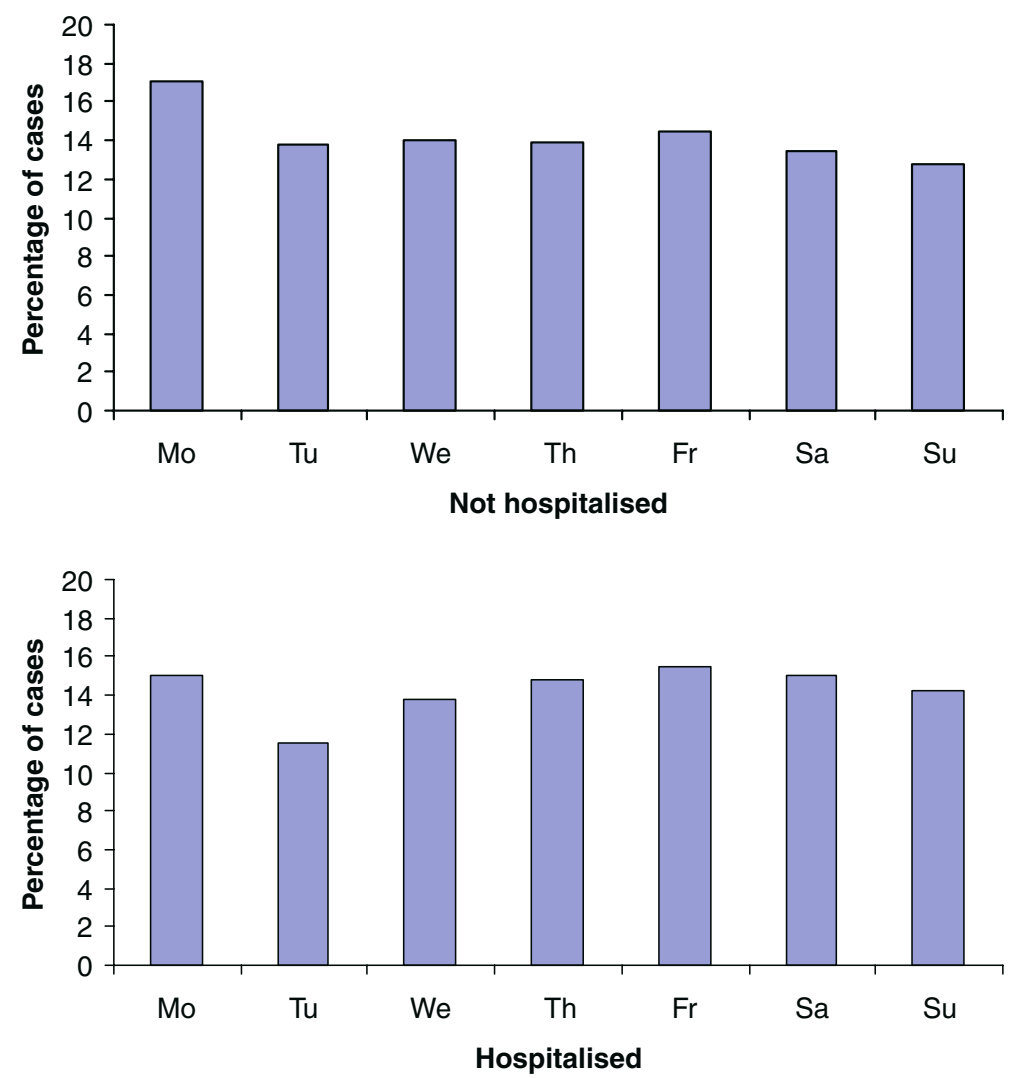

Figure 2. Sudden cardiac deaths in Rotterdam, by day of the week in hospitalised and non-hospitalised individuals. 
Finding circadian variations in disease incidence seems logical given the daily variations in physiological parameters. However, since the week is an arbitrary division of time, the reason for an excess of coronary heart disease on Mondays is less straightforward. Also, most of the studies describe weekly patterns for cardiovascular disease, but not for other conditions like cancer, COPD related outcome or fractures. Seasonal variations however have been described for COPD related diseases and fractures. In the case of weekly variation in incidence of cardiovascular events, triggers are most likely external, in the absence of weekly biological rhythms. Mental stress of starting a new working week and a relative increase in activity has been suggested as determinants of the Monday peak [19]. Also, alcohol use in triggering arrhythmias have been indicated [20]. Our finding of an attenuation in the Monday peak in hospitalised patients is in accordance with this line of thought since hospitalisation generally results in lower activity levels, a reduced variability in activity from day to day and a diminished difference in activity between day and night. This finding is supported by results from a report by Evans et al. [21], who found that the Monday peak was clearest in patient with no previous admission for coronary heart disease dying outside hospital, and absent in hospitalised patients.

The presence of different patterns of weekly variation in persons over and below 65 years of age is an area of conflicting views. Peters et al. [22] report that the subgroup of patients $<65$ years but with previous cardiovascular disease did not display statistically significant peaks, whereas the $>65$ year-old subgroup did. In contrast, results from a population based study showed that the Monday peak was more pronounced in patients under 65 than in those aged 65 or over [23]. Our study may be viewed in line with that report, although the confidence limits in our study between the age groups overlap considerably.

In summary, our study shows that there is a clear peak incidence of sudden cardiac death on Monday compared to the rest of the week.

\section{References}

1. Cohen MC, Rohtla KM, Lavery CE, Muller JE, Mittleman MA. Meta-analysis of the morning excess of acute myocardial infarction and sudden cardiac death. Am J Cardiol 1997; 79: 1512-1516.

2. Oberg AL, Ferguson JA, McIntyre LM, Horner RD. Incidence of stroke and season of the year: evidence of an association. Am J Epidemiol 2000; 152: 558564.

3. Arntz HR, Muller-Nordhorn J, Willich SN. Cold Monday mornings prove dangerous: epidemiology of sudden cardiac death. Curr Opin Crit Care 2001; 7: 139-144.
4. Rabkin SW, Mathewson FA, Tate RB. Chronobiology of cardiac sudden death in men. JAMA 1980; 244: 1357-1358.

5. Willich SN, Maclure M, Mittleman M, Arntz HR, Muller JE. Sudden cardiac death. Support for a role of triggering in causation. Circulation 1993; 87: 1442-1450.

6. Muller JE, Abela GS, Nesto RW, Tofler GH. Triggers, acute risk factors and vulnerable plaques: the lexicon of a new frontier. J Am Coll Cardiol 1994; 23: 809-813.

7. Tofler GH, Stone PH, Maclure M, Edelman E, Davis $\mathrm{VG}$, Robertson T et al. Analysis of possible triggers of acute myocardial infarction (the MILIS study). Am J Cardiol 1990; 66: 22-27.

8. Kauhanen J, Kaplan GA, Goldberg DE, Salonen JT. Beer binging and mortality: results from the Kuopio ischaemic heart disease risk factor study, a prospective population based study. Br Med J 1997; 315: 846-851.

9. Witte DR, Bots ML, Hoes AW, Grobbee DE. Cardiovascular mortality in Dutch men during 1996 European football championship: longitudinal population study. Br Med J 2000; 321: 1552-1554.

10. Hoes AW, Grobbee DE, Lubsen J, Man in 't Veld AJ, van der DE, Hofman A. Diuretics, beta-blockers, and the risk for sudden cardiac death in hypertensive patients. Ann Intern Med 1995; 123: 481-487.

11. Servoss SJ, Januzzi JL, Muller JE. Triggers of acute coronary syndromes. Prog Cardiovasc Dis 2002; 44 : 369-380.

12. Ridker PM, Manson JE, Buring JE, Muller JE, Hennekens $\mathrm{CH}$. Circadian variation of acute myocardial infarction and the effect of low-dose aspirin in a randomized trial of physicians. Circulation 1990; 82: 897-902.

13. Sayer JW, Wilkinson P, Ranjadayalan K, Ray S, Marchant B, Timmis AD. Attenuation or absence of circadian and seasonal rhythms of acute myocardial infarction. Heart 1997; 77: 325-329.

14. Willich SN, Linderer T, Wegscheider K, Leizorovicz A, Alamercery I, Schroder R. Increased morning incidence of myocardial infarction in the ISAM Study: absence with prior beta-adrenergic blockade. ISAM Study Group. Circulation 1989; 80: 853-858.

15. Woods KL, Fletcher S, Jagger C. Modification of the circadian rhythm of onset of acute myocardial infarction by long-term antianginal treatment. Br Heart $\mathbf{J}$ 1992; 68: 458-461.

16. Yamasaki F, Seo H, Furuno T, et al. Effect of age on chronological variation of acute myocardial infarction onset: studyin Japan. Clin ExpHypertens 2002; 24: 1-9.

17. Mitler MM, Hajdukovic RM, Shafor R, Hahn PM, Kripke DF. When people die. Cause of death versus time of death. Am J Med 1987; 82: 266-274.

18. Morning peak in the incidence of myocardial infarction: experience in the ISIS-2 trial. ISIS-2 (Second International Study of Infarct Survival) Collaborative Group. Eur Heart J 1992; 13: 594-598.

19. Martyn C. Hebdomadal rhythms of the heart. BMJ 2000; 321: 1542-1543.

20. Chenet L, Britton A, Kalediene R, Petrauskiene J. Daily variations in deaths in Lithuania: the possible contribution of binge drinking. Int J Epidemiol 2001; 30(4): 743-748.

21. Evans C, Chalmers J, Capewell S, Redpath A, Finlayson A, Boyd J et al. "I don't like Mondays"-day of 
the week of coronary heart disease deaths in Scotland: study of routinely collected data. Br Med J 2000; 320: 218-219.

22. Peters RW, Brooks MM, Zoble RG, Liebson PR, Seals AA. Chronobiology of acute myocardial infarction: cardiac arrhythmia suppression trial (CAST) experience. Am J Cardiol 1996; 78: 1198-1201.

23. Arntz HR, Willich SN, Schreiber C, Bruggemann T, Stern R, Schultheiss HP. Diurnal, weekly and seasonal variation of sudden death. Population-based analysis of 24,061 consecutive cases. Eur Heart J 2000; 21: $315-320$.

Address for correspondence: Dr M.L. Bots, Julius Center for Health Sciences and Primary Care, Huispostnummer Str 6.131, University Medical Center Utrecht, Heidelberglaan 100, 3584 CX Utrecht, The Netherlands

Phone: + 31-30-250-9352; Fax: + 31-30-250-5485

E-mail: m.l.bots@jc.azu.nl; www.juliuscenter.nl 